\title{
Association of African-American Ethnicity and Smoking Status with Total and Individual Damage Index in Systemic Lupus Erythematosus
}

\author{
Romy Kallas, M.D. ${ }^{1}$ [Lupus Fellow], Jessica Li, M.P.H. ${ }^{1}$ [Biostatistician], Michelle Petri, \\ M.D., M.P.H. ${ }^{1}$ [Professor of Medicine] \\ ${ }^{1}$ Division of Rheumatology, Johns Hopkins University School of Medicine, 1830 East Monument \\ Street, Suite 7500, Baltimore, MD 21205, USA
}

\section{Abstract}

Introduction-Smoking has been associated with increased incidence, severity of cutaneous lupus, and lupus activity. We looked at the association of both smoking and ethnicity with the individual damage items from the SLICC/ACR Damage Index.

\begin{abstract}
Methods-Poisson regression was used to model the total SLICC/ACR Damage Index score against ever smoking. Cox regression was used to assess the relationship between time to individual damage items and ever smoking. Furthermore, we compared SLICC/ACR Damage Index items among African-American and Caucasian ever smokers.
\end{abstract}

\begin{abstract}
Results-The study included 2629 patients, 52.6\% Caucasian and 39.3\% African-American. The prevalence of ever smokers was $35.8 \%$. There was no significant difference in total SLICC/ACR Damage Index score between ever smokers and never smokers after adjustment for ethnicity, gender, age at diagnosis, and years of education. Ever smokers had more atherosclerotic cardiovascular damage and skin damage compared to non-smokers. Caucasian SLE patients who ever smoked were more likely to have muscle atrophy and atherosclerosis compared to Caucasian non-smokers. African-American patients who ever smoked were more likely to have skin damage compared to African-American non-smokers. African-Americans who smoked were more likely to have many more damage items (cataract, renal damage, pulmonary hypertension, cardiomyopathy, deforming or erosive arthritis, avascular necrosis, skin damage, and diabetes) compared to Caucasians who smoked.
\end{abstract}

Conclusion-Our analysis proved the major effect of smoking on cardiovascular and cutaneous damage. Surprisingly, cardiovascular damage items had higher hazard ratios in Caucasian smokers than non-smokers while skin damage items hazard ratios were higher in African-American smokers compared to non-smokers.

\footnotetext{
Corresponding author: Romy Kallas M.D., rkallas1@jhmi.edu, Phone: 410-955-9114, Fax: 410-614-0498.

Conflict of interest

The authors have no potential conflict of interest with respect to the research, authorship, and/ or publication of this article.

Ethics approval

All patients gave written informed consent before taking part in the Hopkins Lupus Cohort. The Johns Hopkins University School of Medicine Institutional Review Board approved the Hopkins Lupus Cohort on an annual basis.
} 


\section{Keywords}

Systemic lupus erythematosus; SLICC/ACR Damage Index; Smoking; Ethnicity

\section{Introduction}

Organ damage, measured by the Systemic Lupus Erythematosus International Collaborating Clinics/American College of Rheumatology (SLICC/ACR) Damage Index (SDI) [1, 2], is closely associated with increased morbidity and mortality in patients with SLE [3-5]. Previous clinical studies have established high age at diagnosis, male gender, AfricanAmerican ethnicity, low income, low education level, and corticosteroid use as factors contributing to organ damage in SLE patients [5-7].

In SLE, smoking increased lupus incidence [8-12], severity of cutaneous lupus [13-17], and lupus activity $[14,18,19]$. Response to hydroxychloroquine [13, 20-23] and belimumab $[24,25]$ was decreased in smokers compared to non-smokers, particularly muco-cutaneous manifestations. Smoking rates are higher in African-Americans, in the United States [26]. Several studies have looked at the association between smoking and SLICC/ACR Damage Index scores [7, 18, 27-29]. Three studies exclusively evaluated the effect of smoking on cutaneous damage with conflicting conclusions [14, 19, 29]. Ward et al studied 160 patients from an inception cohort, predominantly African-American, at Duke University and showed that progression to end-stage renal disease in lupus nephritis was more rapid among smokers. The median time to end-stage renal disease among smokers was 145 months compared to greater than 273 months in non-smokers [30]. In an analysis of the LUMINA cohort, a multi-ethnic cohort of around 500 SLE patients, patients who smoked had an increased risk of vascular events which included cardiovascular, cerebrovascular, and peripheral vascular events compared to patients who did not smoke [31].

SLE manifestations and outcomes are known to be affected by ethnicity. Not only does the African-American population have a higher incidence and prevalence of SLE [32, 33] but also more severe clinical manifestations, particularly discoid rash and nephritis [32-34], higher disease activity [35] and damage [36] compared to Caucasians.

The literature lacks large, longitudinal cohort studies that evaluate the effects of smoking on organ damage in SLE patients in different ethnicities. We determined the association between smoking status on total, as well as individual, damage items in SLE. The Hopkins Lupus Cohort, consisting predominantly of Caucasian and African-American patients, allowed us to look at the role of African-American ethnicity.

\section{Methods}

\section{The Hopkins Lupus Cohort}

The Hopkins Lupus Cohort is a longitudinal cohort of patients diagnosed with SLE at the Hopkins Lupus Center. The cohort was established in 1987 and has been approved by the Johns Hopkins University School of Medicine Institutional Review Board on a yearly basis. All patients gave written informed consent. Data were collected prospectively during 
participation in the Hopkins Lupus Cohort during quarterly visits, by protocol. At cohort entry, a detailed clinical history was obtained.

\section{The SLICC/ACR Damage Index (SDI)}

SLICC/ACR Damage Index is a validated tool that was developed to measure damage, defined as irreversible organ dysfunction, present for 6 months or longer, regardless of etiology, in all organ systems [1,2]. The SDI was calculated based on organ damage that occurred after diagnosis with SLE until the last visit. The dependent variable was time from SLE diagnosis to a damage event.

\section{Smoking status}

The smoking status was obtained from the patient and updated at each patient visit. In our analysis we looked at ever (past or current) versus never smoking status. There was no quantification of cigarette use available in the cohort database.

\section{Demographic variables}

The demographic factors included age at diagnosis, gender, ethnicity, education and annual household income. Education was categorized into less or equal to 12 years and more than 12 years. Income was measured as total annual household income at first visit, falling into 3 categories $<\$ 30,000, \$ 30,000-\$ 65,000$ and $>\$ 65,000$.

\section{Statistical analysis}

The chi-square test was used to explore the difference in patient characteristics between ever smokers and non-smokers. Poisson regression was used to model the total SLICC/ACR Damage Index score against ever smoking. Cox regression was used to assess the relationship between time to individual damage items and ever smoking. We also looked at this relationship separately for African-American patients and Caucasian patients. The adjusted hazard ratio (HR) and 95\% confidence intervals were reported. For each damage item, patients who had a damage diagnosis prior to SLE diagnosis were excluded in the analysis.

\section{Results}

The study included 2629 patients. Of these patients, $92.1 \%$ were female, $52.6 \%$ Caucasian and $39.3 \%$ African-American. The mean age at SLE diagnosis was 32.3 years. Fifty percent of the patients were diagnosed with SLE under the age of 30 years, $32.8 \%$ between the age of 30-44, $13.7 \%$ between the age of 45 and 59, and 3.5\% diagnosed at the age of 60 and over. The prevalence of smoking was $35.8 \%$ for all cohort patients, $36.0 \%$ in AfricanAmerican patients and $38.1 \%$ in Caucasian patients. Smokers had lower education, lower income levels, and higher prevalence of alcohol and drug use. Patient sociodemographic characteristics are detailed in Table 1.

Using a Poisson regression model we showed that smokers did not have increased total damage compared to non-smokers after adjusting for gender, ethnicity, age at diagnosis, and education $(\mathrm{HR}=1.03, \mathrm{p}$-value $=0.5172)$. This was true as well after stratification for 
ethnicity: African-American $(\mathrm{HR}=1, \mathrm{p}-\mathrm{value}=0.9922)$ vs. Caucasians $(\mathrm{HR}=1.06$, $\mathrm{p}$ - value $=0.3643$ ).

Table 2 shows the cox regression results to assess the relationship between time to SLICC/ACR Damage Index items and smoking. We first compared ever smokers to nonsmokers in the entire cohort. We then looked at this relationship separately for AfricanAmerican patients and Caucasian patients. Adjusted hazard ratios (HR) and 95\% confidence intervals were reported. Smoking was an independent predictor for coronary artery disease (angina or coronary artery bypass and myocardial infarction), claudication, and skin damage. After stratification by ethnicity, Caucasians who ever smoked were at higher risk of coronary artery disease and muscle atrophy compared to non-smokers. Gonadal failure in Caucasians was near significance. In African-American patients, smoking remained an independent predictor of any cutaneous damage (particularly extensive scarring). There was an inverse relationship between smoking and cranial or peripheral neuropathy, pulmonary fibrosis and osteoporosis in African-American patients.

Table 3 shows the comparison between African-American smokers and Caucasian smokers regarding time to SLICC/ACR Damage Index items. African-American smokers were at higher risk of cataract, renal damage, pulmonary hypertension, cardiomyopathy, deforming or erosive arthritis, avascular necrosis, skin damage, and diabetes compared to Caucasian smokers. However, African-American smokers were less likely to have infarction or resection of bowel and osteoporosis with fracture or vertebral collapse compared to Caucasian smokers.

\section{Discussion}

This study is the largest cohort study to date evaluating the effect of smoking on the cumulative SLICC/ACR Damage Index and its individual damage items. It is the only study that examined the effect of smoking on individual items of the SLICC/ACR Damage Index in terms of Caucasians vs. African-American ethnicity. In contrast with the general U.S. population, African-Americans in the cohort did not have a higher frequency of smoking than Caucasians.

First, surprisingly, we found that ever smokers did not have higher total SLICC/ACR Damage Index scores compared to non-smokers. This is in agreement with Ekblom-Kullberg et al, who found that smokers and non-smokers not only had comparable SLICC/ACR Damage Indices, but also that current smokers had lower disease activity and lower antidsDNA levels [37]. In our cohort, however, smoking was not associated with higher antidsDNA or mean SLEDAI scores (p-values $=0.7680,0.9100$ respectively). Turchin et al and Kim et al also did not find any association between total SLEDAI-2K nor total Damage Index scores in current smokers compared to non-smokers in predominantly Caucasian and Asian cohorts respectively [14, 29]. In mice, Rubin et al showed a negative association between smoking and anti-DNA and anti-chromatin IgG levels [38]. This was confirmed by extending the study to newly diagnosed SLE patients on no treatment [38]. These studies suggested an immunosuppressive role of nicotine through its effect on $\mathrm{T}$ cell ability to transmit antigen-receptor-mediated signals [39]. 
On the other hand, studies by Legge et al and Montes et al (evaluating total damage in Caucasian and Brazilian SLE patients, respectively), found an association between smoking and total SLICC/ACR Damage Index [7, 28] (p-values=0.02 in both studies). Ghaussy et al, analyzing 111 patients predominantly of Hispanic ethnicity, found a non-significant trend towards higher cumulative damage in current smokers (SDI scores were $4.34 \pm 2.41,3.89 \pm$ 2.68 , and $3.60 \pm 2.85$ for current, ex-, and never smokers, respectively) [18]. In this same study, the mean SLEDAI score was higher in current smokers compared to former and nonsmokers [18]. In a study which included only Caucasian SLE patients, higher titers of antidsDNA was observed in smokers compared to non-smokers [40].

Second, in this study, we demonstrate that smoking was associated with an increased risk of coronary artery disease and peripheral arterial disease. A past analysis, of a subset of our cohort in the atorvastatin intervention trial, showed that smoking was an independent predictor of atherosclerosis progression [41]. In the LUMINA cohort, patients who had arterial thrombotic events (myocardial infarction, angina, coronary artery bypass graft surgery, stroke, claudication, gangrene, or tissue loss and/or peripheral arterial thrombosis) were more likely to be smokers [42].

Third, smoking worsened cutaneous damage. Our study is in agreement with other studies that demonstrated that smoking worsened cutaneous damage [14]. In fact, several studies identified smoking as a trigger for skin manifestations, mainly discoid lupus [13, 17, 34]. Moreover, smoking appears to decrease the efficacy of hydroxychloroquine in a dosedependent fashion, particularly in cutaneous lupus [13, 20-23]. Turchin et al demonstrated that current smokers had trends towards higher lupus cutaneous activity, largely driven by the specific type of active lupus rash [14]. More cutaneous manifestations and poorer response to antimalarial treatment are valid explanations for the greater cutaneous damage in smokers.

Fourth, although ethnicity has been identified as a risk modifier in the burden of tobaccorelated diseases [43], our study is the first to show the differential effect of smoking on the SLICC/ACR Damage Index items depending on the ethnicity of SLE patients. This is in support of possible gene-environment interactions in altering the effect of cigarette smoking on clinical and serologic phenotypes. African-American smokers had many more damage items compared to Caucasian smokers. Among smokers, African-Americans were at higher risk of cataract, renal damage, pulmonary hypertension, cardiomyopathy, deforming or erosive arthritis, avascular necrosis, skin damage, and diabetes, whereas there was only a higher risk of osteoporosis with fracture and gastrointestinal infarction in Caucasian smokers.

Fifth, smoking had a greater effect on skin damage in African-American patients. In contrast, Caucasians who ever smoked had higher hazard ratios of atherosclerotic and arterial thrombotic damage compared to non-smokers. SLE patients who ever smoked had a 3-fold increase in cardiovascular events compared to nonsmokers [31]. In a prospective study, African-American patients were at an increased risk of cardiovascular events compared to Caucasians [44]. The differential effect of smoking in Caucasians observed in our study has never been reported before. 
Sixth, Caucasian ever smokers were more likely to have muscle atrophy compared to Caucasian non-smokers. The association between long-term smoking and muscle atrophy, in the general population, is well established [45]. Moreover, a study of 465 patients with polymyositis, showed that Caucasian ever-smokers were more likely to have polymyositis, compared to never-smokers. This association was not statistically significant in AfricanAmericans [46].

Seventh, studies in the general population found any exposure to tobacco (current, ever and second hand smoking) was associated with an increased risk of infertility and early menopause [47]. In our study, the effect of smoking on gonadal failure was close to significance only in Caucasians.

Eight, smoking was actually protective against some types of organ damage. Our findings suggest that there is a relationship between smoking and lower risk of cranial neuropathy in African-American patients. This finding is surprising, as it is well-known that smoking increases the risk of neuropathy in diabetic patients [48]. Epidemiologic studies have found an inverse relationship between smoking and Parkinson's disease. The protective effect is thought to be explained by the effects of nicotine on the dopaminergic system. We have no explanation for the protective effect in SLE.

Moreover, there was an inverse relationship between smoking and pulmonary fibrosis in African-American patients. In the general population, only a fraction of chronic smokers develop chronic lung disease. The proteomes of lungs from chronic smokers, non-smokers, and ex-smokers were evaluated in one study [49]. There was an upregulation of unfolded protein response in smokers. Unfolded protein response is responsible for inducing proteins responsible for protection against antioxidant injury and inflammation [49]. Upregulation of such a response is a possible explanation of the protective role of smoking on pulmonary fibrosis in African-Americans.

Ninth, we failed to find an association between smoking and renal damage, osteoporotic fractures, and cataract in our patients. Smokers were not at higher risk of developing kidney damage. This is in harmony with our past report that did not find an association between smoking and renal insufficiency and renal failure [50]. McAlindon et al also did not find that smokers were at a higher risk of glomerulonephritis [51]. Ward et al, however, demonstrated that the median time to end- stage renal disease among smokers was 145 compared to greater than 273 months in non-smokers (p-value $=0.04$ ) [30].

A previous report from our cohort showed that current and ever smoking status was associated with increased musculoskeletal damage [52]. We did not find an association between smoking and osteoporosis or avascular necrosis in this larger sample. Cataract is the most common ocular damage in SLE patients [53]. Despite its known association in the general population, smoking was not a risk factor for cataract in our SLE patients. This is in agreement with a previous analysis of modifiable risk factors associated with cataract in our cohort [53].

The strengths of our study include the large sample size that allowed us to evaluate the effect of smoking on individual SLICC/ACR Damage Index items. Our study does have limitations 
and potentials for bias, as we studied only a single aspect of smoking (ever versus never smoker), we could not take into account second hand smoking, and did not quantify smoking.

\section{Conclusion}

Smoking did not increase the total SLICC/ACR Damage Index in SLE. Our analysis proved the major effect of smoking was on cardiovascular damage (angina, coronary bypass, myocardial infarction and claudication) and cutaneous damage. There was a differential effect of smoking according to ethnicity. Cardiovascular damage items had higher hazard ratios in Caucasian smokers. Extensive cutaneous scarring hazard ratios were higher in African-American smokers. African-American smokers had more items of organ damage than Caucasian smokers.

\section{Acknowledgments}

Funding Source: The Hopkins Lupus Cohort was funded by NIH Grant R01-AR06957.

\section{References}

1. Gladman D, Ginzler E, Goldsmith C, et al. (1996) The development and initial validation of the Systemic Lupus International Collaborating Clinics/American College of Rheumatology damage index for systemic lupus erythematosus. Arthritis Rheum 39:363-9 [PubMed: 8607884]

2. Gladman DD, Urowitz MB, Goldsmith CH, et al. (1997) The reliability of the Systemic Lupus International Collaborating Clinics/American College of Rheumatology Damage Index in patients with systemic lupus erythematosus. Arthritis Rheum 40:809-13. [PubMed: 9153540]

3. Alarcon GS, McGwin Jr. G, Bastian HM, et al. (2001) Systemic lupus erythematosus in three ethnic groups. VII [correction of VIII]. Predictors of early mortality in the LUMINA cohort. LUMINA Study Group. Arthritis Rheum 45:191-202. [PubMed: 11324784]

4. Rahman P, Gladman DD, Urowitz MB, et al. (2001) Early damage as measured by the SLICC/ACR damage index is a predictor of mortality in systemic lupus erythematosus. Lupus 10:93-6. [PubMed: 11237132]

5. Bruce IN, O'Keeffe AG, Farewell V, et al. (2015) Factors associated with damage accrual in patients with systemic lupus erythematosus: results from the Systemic Lupus International Collaborating Clinics (SLICC) Inception Cohort. Ann Rheum Dis 74:1706-1713. [PubMed: 24834926]

6. Petri M, Purvey S, Fang H, Magder LS (2012) Predictors of organ damage in systemic lupus erythematosus: the Hopkins Lupus Cohort. Arthritis Rheum 64:4021-8. [PubMed: 22932985]

7. Legge A, Doucette S, Hanly JG (2016) Predictors of Organ Damage Progression and Effect on Health-related Quality of Life in Systemic Lupus Erythematosus. J Rheumatol 43:1050-1056. [PubMed: 27084911]

8. Nagata C, Fujita S, Iwata H, et al. (1995) Systemic lupus erythematosus: a case-control epidemiologic study in Japan. Int J Dermatol 34:333-337 [PubMed: 7607794]

9. Hardy CJ, Palmer BP, Muir KR, et al. (1998) Smoking history, alcohol consumption, and systemic lupus erythematosus: A case-control study. Ann Rheum Dis 57:451-455. [PubMed: 9797548]

10. Ghaussy NO, Sibbitt WL, Qualls CR (2001) Cigarette smoking, alcohol consumption, and the risk of systemic lupus erythematosus: a case-control study. J Rheumatol 28:2449-53 [PubMed: 11708417]

11. Kiyohara C, Washio M, Horiuchi T, et al. (2012) Cigarette smoking, alcohol consumption, and risk of systemic lupus erythematosus: a case-control study in a Japanese population. J Rheumatol 39:1363-1370. [PubMed: 22589266] 
12. Cozier YC, Barbhaiya M, Castro-Webb N, et al. (2019) Relationship of Cigarette Smoking and Alcohol Consumption to Incidence of Systemic Lupus Erythematosus in a Prospective Cohort Study of Black Women. Arthritis Care Res (Hoboken) 71:671-677. [PubMed: 30091287]

13. Miot HA, Bartoli Miot LD, Haddad GR (2005) Association between Discoid Lupus erythematosus and Cigarette Smoking. Dermatology 211:118-122. [PubMed: 16088157]

14. Turchin I, Bernatsky S, Clarke A, et al. (2009) Cigarette Smoking and Cutaneous Damage in Systemic Lupus Erythematosus. J Rheumatol 36:3-6.

15. Boeckler P, Cosnes A, Francès C, et al. (2009) Association of cigarette smoking but not alcohol consumption with cutaneous lupus erythematosus. Arch Dermatol 145:1012-6. [PubMed: 19770440]

16. Piette EW, Foering KP, Chang AY, et al. (2012) Impact of smoking in cutaneous lupus erythematosus. Arch Dermatol 148:317-22. [PubMed: 22105815]

17. Santiago-Casas Y, Vilá LM, McGwin G, et al. (2012) Association of discoid lupus erythematosus with clinical manifestations and damage accrual in a multiethnic lupus cohort. Arthritis Care Res (Hoboken) 64:704-712. [PubMed: 22190480]

18. Ghaussy NO, Sibbitt WL, Bankhurst AD, Qualls CR (2003) Cigarette smoking and disease activity in systemic lupus erythematosus. J Rheumatol 30:1215-1221 [PubMed: 12784392]

19. Bourre-Tessier J, Peschken CA, Bernatsky S, et al. (2013) Association of smoking with cutaneous manifestations in systemic lupus erythematosus. Arthritis Care Res 65:1275-1280.

20. Rahman P, Gladman DD, Urowitz MB (1998) Smoking interferes with efficacy of antimalarial therapy in cutaneous lupus. J Rheumatol 25:1716-9 [PubMed: 9733451]

21. Jewell ML, McCauliffe DE (2000) Patients with cutaneous lupus erythematosus who smoke are less responsive to antimalarial treatment. J Am Acad Dermatol 42:983-987. [PubMed: 10827400]

22. Moghadam-Kia S, Chilek K, Gaines E, et al. (2009) Cross-sectional Analysis of a Collaborative Web-Based Database for Lupus Erythematosus-Associated Skin Lesions. Arch Dermatol 145: 255-60. [PubMed: 19289753]

23. Chasset F, Francès C, Barete S, et al. (2015) Influence of smoking on the efficacy of antimalarials in cutaneous lupus: A meta-analysis of the literature. J Am Acad Dermatol 72:634-639. [PubMed: 25648824]

24. Parodis I, Sjöwall C, Jönsen A, et al. (2017) Smoking and pre-existing organ damage reduce the efficacy of belimumab in systemic lupus erythematosus. Autoimmun Rev 16:343-351. [PubMed: 28216072]

25. Parodis I, Gomez A, Frodlund M, et al. (2018) Smoking reduces the efficacy of belimumab in mucocutaneous lupus. Expert Opin Biol Ther 18:911-920. [PubMed: 29958508]

26. Department of Health and Human Services, Centers for Disease Control and Prevention, National Center for Chronic Disease Prevention and Health Promotion, Office on Smoking and Health (1998) Tobacco Use Among U.S. Racial/Ethnic Minority Groups-African Americans, American Indians and Alaska Natives, Asian Americans and Pacific Islanders, and Hispanics: A Report of the Surgeon General. https://www.cdc.gov/tobacco/data_statistics/sgr/1998/complete_report.

27. Ekblom-Kullberg S, Kautiainen H, Alha P, et al. (2014) Smoking, disease activity, permanent damage and dsDNA autoantibody production in patients with systemic lupus erythematosus. Rheumatol Int 34:341-345. [PubMed: 24170320]

28. Montes RA, Mocarzel LO, Lanzieri PG, et al. (2016) Smoking and Its Association With Morbidity in Systemic Lupus Erythematosus Evaluated by the Systemic Lupus International Collaborating Clinics/American College of Rheumatology Damage Index: Preliminary Data and Systematic Review. Arthritis Rheumatol 68:441-448. [PubMed: 26359794]

29. Kim SK, Lee SS, Choe JY, et al. (2017) Effect of alcohol consumption and smoking on disease damage in systemic lupus erythematosus: data from the Korean Lupus Network (KORNET) registry. Lupus 26:1540-1549. [PubMed: 28478697]

30. Ward MM, Studenski S (1992) Clinical prognostic factors in lupus nephritis. The importance of hypertension and smoking. Arch Intern Med 152:2082-8 [PubMed: 1417382]

31. Toloza SMA, Uribe AG, McGwin G, et al. (2004) Systemic lupus erythematosus in a multiethnic US cohort (LUMINA): XXIII. Baseline predictors of vascular events. Arthritis Rheum 50:39473957. [PubMed: 15593203] 
32. Somers EC, Marder W, Cagnoli P, et al. (2014) Population-based incidence and prevalence of systemic lupus erythematosus: the Michigan Lupus Epidemiology and Surveillance program. Arthritis Rheumatol (Hoboken, NJ) 66:369-78.

33. Lim SS, Bayakly AR, Helmick CG, et al. (2014) The Incidence and Prevalence of Systemic Lupus Erythematosus, 2002-2004: The Georgia Lupus Registry. Arthritis Rheumatol 66:357-368. [PubMed: 24504808]

34. Petri M (2000) Hopkins Lupus Cohort. Rheum Dis Clin North Am 26:199-213. [PubMed: 10768209]

35. Alarcón GS, Calvo-Alén J, McGwin G, et al. (2006) Systemic lupus erythematosus in a multiethnic cohort: LUMINA XXXV. Predictive factors of high disease activity over time. Ann Rheum Dis 65:1168-74. [PubMed: 16905579]

36. Alarcón GS, McGwin G, Bartolucci AA, et al. (2001) Systemic lupus erythematosus in three ethnic groups: IX. Differences in damage accrual. Arthritis Rheum 44:2797-2806. [PubMed: 11762940]

37. Ekblom-Kullberg S, Kautiainen H, Alha P, et al. (2014) Smoking, disease activity, permanent damage and dsDNA autoantibody production in patients with systemic lupus erythematosus. Rheumatol Int 34:341-345. [PubMed: 24170320]

38. Rubin RL, Hermanson TM, Bedrick EJ, et al. (2005) Effect of cigarette smoke on autoimmunity in murine and human systemic lupus erythematosus. Toxicol Sci 87:86-96. [PubMed: 15947027]

39. Kalra R, Singh SP, Savage SM, et al. (2000) Effects of cigarette smoke on immune response: chronic exposure to cigarette smoke impairs antigen-mediated signaling in $\mathrm{T}$ cells and depletes IP3-sensitive Ca(2+) stores. J Pharmacol Exp Ther 293:166-71 [PubMed: 10734166]

40. Freemer MM (2006) Association of smoking with dsDNA autoantibody production in systemic lupus erythematosus. Ann Rheum Dis 65:581-584. [PubMed: 16150789]

41. Kiani AN, Post WS, Magder LS, Petri M (2011) Predictors of progression in atherosclerosis over 2 years in systemic lupus erythematosus. Rheumatology (Oxford) 50:2071-2079. [PubMed: 21875880]

42. Calvo-Alen J, Alarcon GS, Tew MB, et al. (2006) Systemic lupus erythematosus in a multiethnic US cohort: XXXIV. Deficient mannose-binding lectin exon 1 polymorphisms are associated with cerebrovascular but not with other arterial thrombotic events. Arthritis Rheum 54:1940-1945. [PubMed: 16729310]

43. Jones MR, Tellez-Plaza M, Navas-Acien A (2013) Smoking, Menthol Cigarettes and All-Cause, Cancer and Cardiovascular Mortality: Evidence from the National Health and Nutrition Examination Survey (NHANES) and a Meta-Analysis. PLoS One 8:e77941. [PubMed: 24205038]

44. Barbhaiya M, Feldman CH, Guan H, et al. (2017) Race/Ethnicity and Cardiovascular Events Among Patients With Systemic Lupus Erythematosus. Arthritis Rheumatol (Hoboken, NJ) 69:1823-1831.

45. Krüger K, Dischereit G, Seimetz M, et al. (2015) Time course of cigarette smoke-induced changes of systemic inflammation and muscle structure. Am J Physiol Lung Cell Mol Physiol 309:L119_ L128. [PubMed: 26001775]

46. Schiffenbauer A, Faghihi-Kashani S, O'Hanlon TP, et al. (2018) The effect of cigarette smoking on the clinical and serological phenotypes of polymyositis and dermatomyositis. Semin Arthritis Rheum 48:504-512. [PubMed: 29703532]

47. Hyland A, Piazza K, Hovey KM, et al. (2016) Associations between lifetime tobacco exposure with infertility and age at natural menopause: the Women's Health Initiative Observational Study. Tob Control 25:706-714. [PubMed: 26666428]

48. Clair C, Cohen MJ, Eichler F, et al. (2015) The Effect of Cigarette Smoking on Diabetic Peripheral Neuropathy: A Systematic Review and Meta-Analysis. J Gen Intern Med 30:1193-1203. [PubMed: 25947882]

49. Kelsen SG, Duan X, Ji R, et al. (2008) Cigarette Smoke Induces an Unfolded Protein Response in the Human Lung. Am J Respir Cell Mol Biol 38:541-550. [PubMed: 18079489]

50. Petri M (2000) Hopkins Lupus Cohort. Rheum Dis Clin North Am 26:199-213. [PubMed: 10768209]

51. McAlindon T, Giannotta L, Taub N, et al. (1993) Environmental factors predicting nephritis in systemic lupus erythematosus. Ann Rheum Dis 52:720-4 [PubMed: 8257208] 
52. Petri M (1995) Musculoskeletal complications of systemic lupus erythematosus in the Hopkins Lupus Cohort: an update. Arthritis Care Res 8:137-45 [PubMed: 7654797]

53. Alderaan K, Sekicki V, Magder LS, Petri M (2015) Risk factors for cataracts in systemic lupus erythematosus (SLE). Rheumatol Int 35:701-708. [PubMed: 25257763] 


\section{Key points}

1. This study is the largest cohort study to date evaluating the effect of smoking on the cumulative SLICC/ACR Damage Index and its individual damage items.

2. It is the only study that examined the effect of smoking on individual items of the SLICC/ACR Damage Index in terms of Caucasians vs. African-American ethnicity.

3. Our analysis proved the major effect of smoking on cardiovascular and cutaneous damage. Compared to non-smokers, Caucasian smokers had higher risk of cardiovascular damage while African-American smokers had more skin damage.

4. African-Americans who smoked were more likely to have many more damage items (cataract, renal damage, pulmonary hypertension, cardiomyopathy, deforming or erosive arthritis, avascular necrosis, skin damage, and diabetes) compared to Caucasians who smoked. 
Table 1:

Patient sociodemographic characteristics of the Hopkins Lupus Cohort by smoking status

\begin{tabular}{|c|c|c|c|c|c|c|c|c|c|}
\hline & \multicolumn{3}{|c|}{ All $(n=2629)$} & \multicolumn{3}{|c|}{ African American $(n=1033)$} & \multicolumn{3}{|c|}{ Caucasian $(n=1382)$} \\
\hline & $\begin{array}{c}\text { Ever } \\
\text { smokers }\end{array}$ & $\begin{array}{c}\text { Never } \\
\text { smokers }\end{array}$ & p-value & $\begin{array}{c}\text { Ever } \\
\text { smokers }\end{array}$ & $\begin{array}{c}\text { Never } \\
\text { smokers }\end{array}$ & p-value & $\begin{array}{c}\text { Ever } \\
\text { smokers }\end{array}$ & $\begin{array}{c}\text { Never } \\
\text { smokers }\end{array}$ & p-value \\
\hline Gender & & & 0.0003 & & & 0.0026 & & & 0.2282 \\
\hline Female & $89.6 \%$ & $93.5 \%$ & & $90.3 \%$ & $95.1 \%$ & & $89.8 \%$ & $91.8 \%$ & $0 \%$ \\
\hline Male & $10.4 \%$ & $6.5 \%$ & & $9.7 \%$ & $4.9 \%$ & & $10.2 \%$ & $8.3 \%$ & \\
\hline $\begin{array}{l}\text { Age at SLE } \\
\text { diagnosis }\end{array}$ & & & $<0.0001$ & & & $<0.0001$ & & & $<0.0001$ \\
\hline$<30$ years & $39.7 \%$ & $55.8 \%$ & & $39.7 \%$ & $57.2 \%$ & & $39.1 \%$ & $52.4 \%$ & \\
\hline $30-44$ years & $36.7 \%$ & $30.7 \%$ & & $38.4 \%$ & $32.9 \%$ & & $35.7 \%$ & $30.6 \%$ & \\
\hline $45-59$ years & $17.7 \%$ & $11.4 \%$ & & $17.6 \%$ & $9.2 \%$ & & $17.9 \%$ & $14 \%$ & \\
\hline $60+$ years & $5.9 \%$ & $2 \%$ & & $4.3 \%$ & $0.8 \%$ & & $7.3 \%$ & $3.1 \%$ & \\
\hline Education & & & $<0.0001$ & & & $<0.0001$ & & & $<0.0001$ \\
\hline$\leq 2$ years & $47.6 \%$ & $24.9 \%$ & & $58.1 \%$ & $31.3 \%$ & & $42.4 \%$ & $21.0 \%$ & \\
\hline$>12$ years & $52.4 \%$ & $75.1 \%$ & & $41.9 \%$ & $68.7 \%$ & & $57.6 \%$ & $79.0 \%$ & \\
\hline Family income & & & $<0.0001$ & & & $<0.0001$ & & & 0.0002 \\
\hline$<\$ 30,000$ & $41.6 \%$ & $25.7 \%$ & & $64.1 \%$ & $40.7 \%$ & & $26.2 \%$ & $17 \%$ & \\
\hline $\begin{array}{c}\$ 30,000- \\
\$ 65,000\end{array}$ & $29.9 \%$ & $34.2 \%$ & & $24.1 \%$ & $31.8 \%$ & & $35.4 \%$ & $35.9 \%$ & \\
\hline$\$ 65,000+$ & $28.5 \%$ & $40.2 \%$ & & $11.8 \%$ & $27.5 \%$ & & $38.4 \%$ & $47.1 \%$ & \\
\hline Insurance & & & $<0.0001$ & & & $<0.0001$ & & & 0.0001 \\
\hline Private & $71.8 \%$ & $82.2 \%$ & & $56.4 \%$ & $70.6 \%$ & & $82.9 \%$ & $90.8 \%$ & \\
\hline MA & $24.8 \%$ & $15.6 \%$ & & $38.4 \%$ & $26.1 \%$ & & $15.1 \%$ & $8.3 \%$ & \\
\hline None & $3.4 \%$ & $2.2 \%$ & & $5.3 \%$ & $3.3 \%$ & & $2 \%$ & $0.9 \%$ & \\
\hline Marital status & & & $<0.0001$ & & & $<0.0001$ & & & 0.0006 \\
\hline Married & $52.2 \%$ & $54.1 \%$ & & $30.5 \%$ & $39.2 \%$ & & $67.3 \%$ & $64.7 \%$ & \\
\hline Single & $28.5 \%$ & $35.4 \%$ & & $43.3 \%$ & $48.4 \%$ & & $17.2 \%$ & $25.6 \%$ & \\
\hline Separated & $3.6 \%$ & $2.4 \%$ & & $5.5 \%$ & $3.4 \%$ & & $2.3 \%$ & $1.6 \%$ & \\
\hline Widowed & $3.6 \%$ & $1.8 \%$ & & $6 \%$ & $2.6 \%$ & & $2.1 \%$ & $1.4 \%$ & \\
\hline Divorced & $12.2 \%$ & $6.2 \%$ & & $14.7 \%$ & $6.4 \%$ & & $11.1 \%$ & $6.8 \%$ & \\
\hline Alcohol abuse & & & $<0.0001$ & & & $<0.0001$ & & & $<0.0001$ \\
\hline Ever & $14.8 \%$ & $2.2 \%$ & & $21.6 \%$ & $1.7 \%$ & & $11 \%$ & $2.6 \%$ & \\
\hline Never & $85.2 \%$ & $97.9 \%$ & & $78.4 \%$ & $98.3 \%$ & & $89 \%$ & $97.4 \%$ & \\
\hline Drug abuse & & & $<0.0001$ & & & $<0.0001$ & & & $<0.0001$ \\
\hline Ever & $14.5 \%$ & $1.6 \%$ & & $21.4 \%$ & $1.7 \%$ & & $10 \%$ & $1.5 \%$ & \\
\hline Never & $85.5 \%$ & $98.4 \%$ & & $78.7 \%$ & $98.3 \%$ & & $90 \%$ & $98.5 \%$ & \\
\hline
\end{tabular}




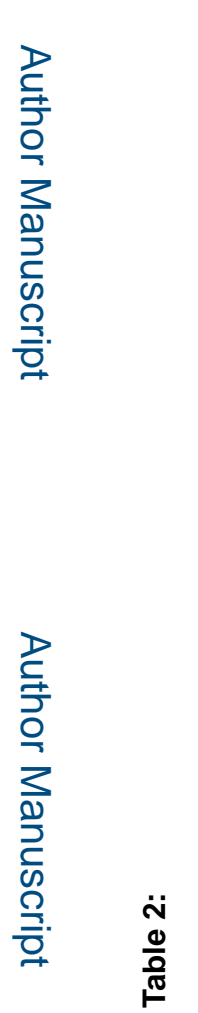

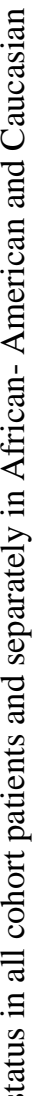

\begin{tabular}{|c|c|c|c|c|c|c|c|c|c|c|c|c|c|c|c|c|c|c|c|c|c|c|c|c|c|}
\hline & 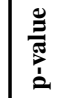 & $\begin{array}{l}\tilde{\hat{\delta}} \\
0 \\
0\end{array}$ & 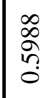 & 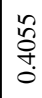 & $\begin{array}{l}\text { ô } \\
\text { on } \\
o\end{array}$ & $y$ & 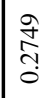 & 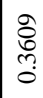 & $\begin{array}{l}\overrightarrow{\widetilde{D}} \\
\stackrel{0}{0}\end{array}$ & $\frac{8}{f}$ & $\begin{array}{l}\frac{0}{n} \\
\stackrel{2}{0}\end{array}$ & $\begin{array}{l}\stackrel{\partial}{\sigma} \\
\stackrel{0}{0}\end{array}$ & $\begin{array}{l}\vec{\alpha} \\
\text { o. } \\
o \\
0\end{array}$ & & 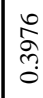 & $\begin{array}{l}\hat{D} \\
\stackrel{2}{a} \\
o\end{array}$ & 今. & & & 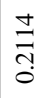 & 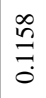 & $\begin{array}{l}\text { त̂̀े } \\
\stackrel{0}{0}\end{array}$ & & $\begin{array}{l}\text { 范 } \\
\text { : }\end{array}$ & $\frac{\text { సे }}{0}$ \\
\hline 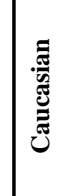 & 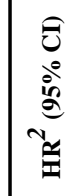 & 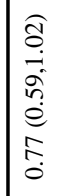 & 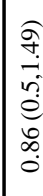 & 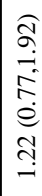 & 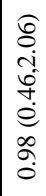 & 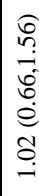 & 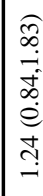 & 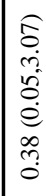 & 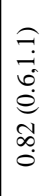 & fo & 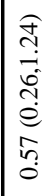 & 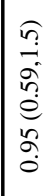 & 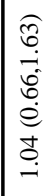 & त̂ & 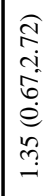 & 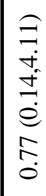 & 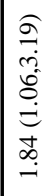 & $\widehat{\widehat{乃}}$ & $\approx$ & 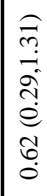 & 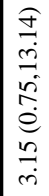 & 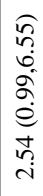 & $\begin{array}{l}\text { ô } \\
\text { j. } \\
\Leftrightarrow\end{array}$ & $\begin{array}{l}\hat{\sigma} \\
\dot{+} \\
\dot{\sigma} \\
\hat{e} \\
\stackrel{e}{+} \\
\stackrel{-}{-}\end{array}$ & 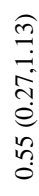 \\
\hline
\end{tabular}

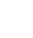

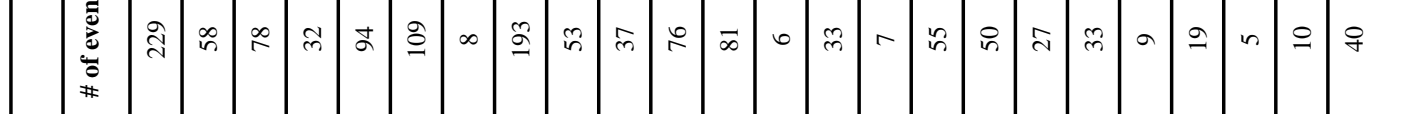

(1)

\begin{tabular}{|c|c|c|c|c|c|c|c|c|c|c|c|c|c|c|c|c|c|c|c|c|c|c|c|c|}
\hline 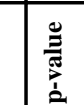 & $\begin{array}{l}0 \\
\hat{a} \\
0 \\
0\end{array}$ & $\begin{array}{l}m \\
\stackrel{n}{0} \\
\stackrel{0}{0}\end{array}$ & $\begin{array}{l}\text { 索 } \\
\text { ḋ }\end{array}$ & હેః & 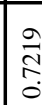 & $\begin{array}{l}\overline{0} \\
\stackrel{0}{0}\end{array}$ & $\begin{array}{l}\text { 党 } \\
\stackrel{0}{0}\end{array}$ & $\begin{array}{l}\text { 文 } \\
\text { a } \\
\stackrel{0}{0}\end{array}$ & ( & \begin{tabular}{l} 
के \\
\multirow{7}{0}{} \\
\multirow{0}{0}{}
\end{tabular} & مิ & 产 & $\grave{\nwarrow}$ & 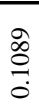 & $\grave{Z}$ & $\begin{array}{c}\mathbb{R} \\
\text { o } \\
0 \\
0\end{array}$ & 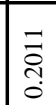 & \begin{tabular}{|l}
$\bar{\alpha}$ \\
$\stackrel{\infty}{0}$ \\
$\tilde{0}$
\end{tabular} & 委 & 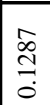 & 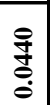 & $\begin{array}{l}\text { Dे } \\
\text { o. } \\
0 \\
0\end{array}$ & & $\begin{array}{c}0 \\
\vdots \\
\vdots \\
0\end{array}$ \\
\hline
\end{tabular}

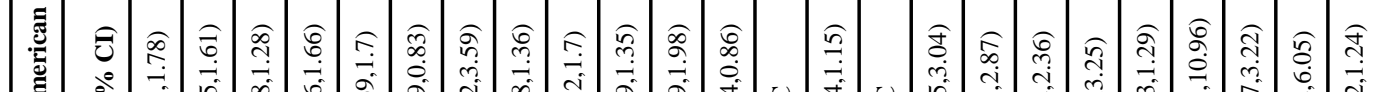

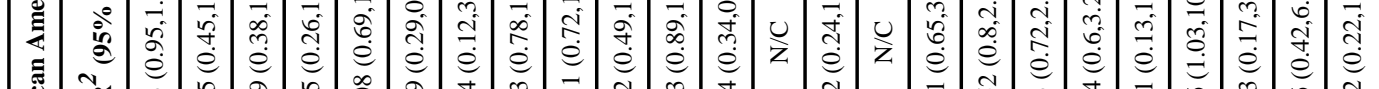

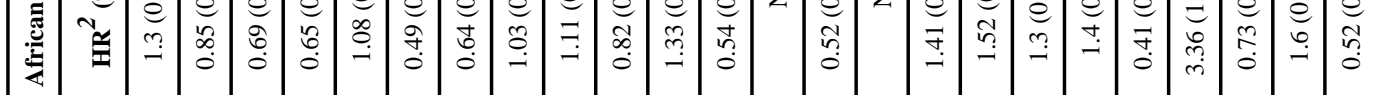

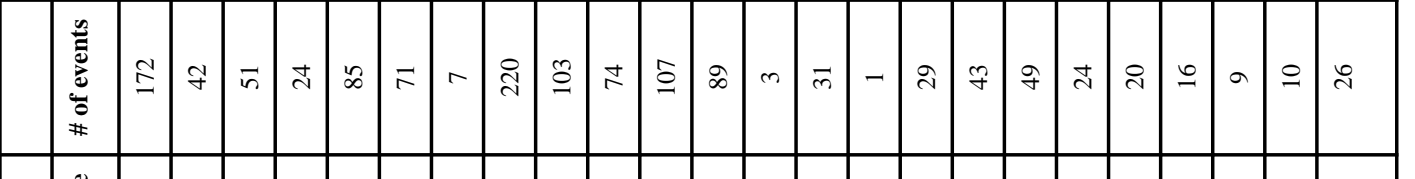

(a)

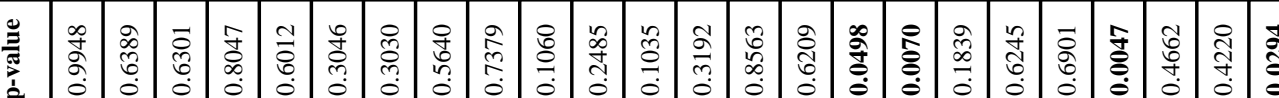

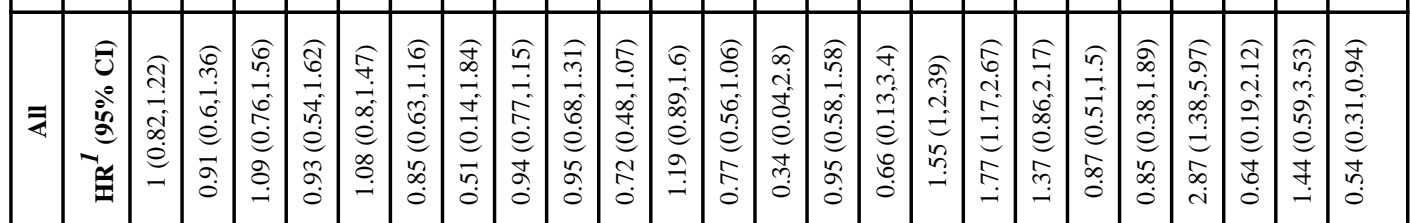

$\stackrel{\square}{.}$

$\frac{\overbrace{}^{\infty}}{g}$

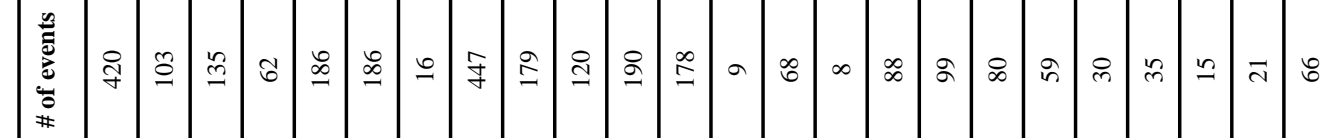

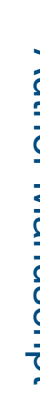

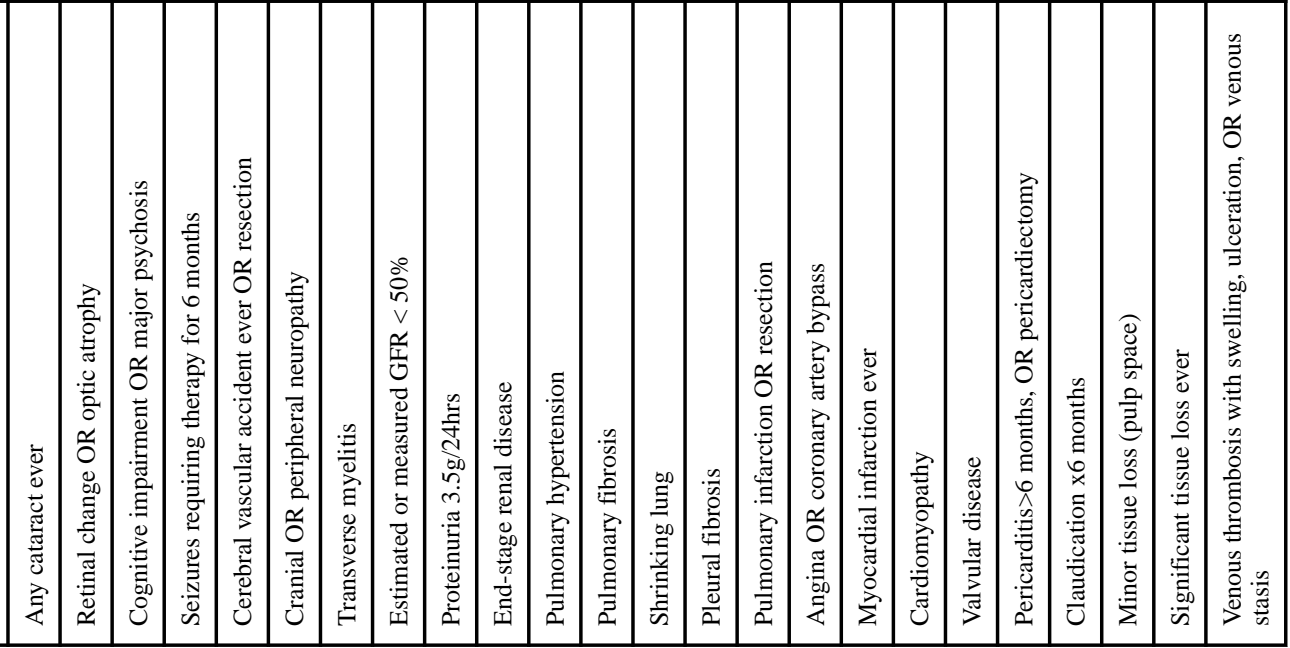

Clin Rheumatol. Author manuscript; available in PMC 2021 February 01. 


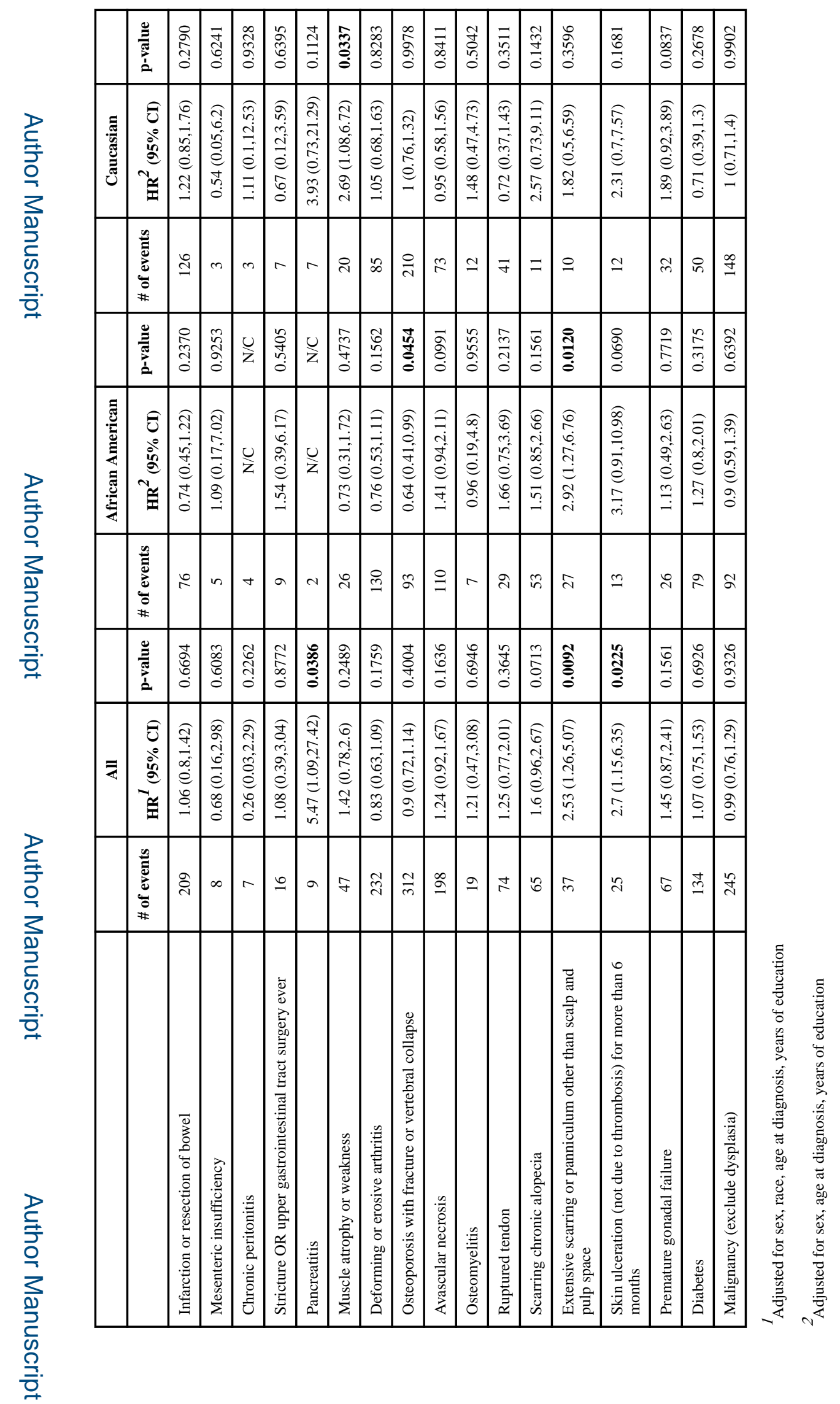

Clin Rheumatol. Author manuscript; available in PMC 2021 February 01. 
Table 3:

Associations between SLICC/ ACR Damage Index items and ethnicity: comparing African Americans and Caucasians ever smokers

\begin{tabular}{|c|c|c|c|}
\hline & \# of events among smokers & $\mathrm{HR}^{1}(95 \% \mathrm{CI})$ & p-value \\
\hline Any cataract ever & 176 & $1.42(1.05,1.93)$ & 0.0240 \\
\hline Retinal change OR optic atrophy & 40 & $0.92(0.48,1.76)$ & 0.7994 \\
\hline Cognitive impairment OR major psychosis & 52 & $0.65(0.36,1.17)$ & 0.1510 \\
\hline Seizures requiring therapy for 6 months & 19 & $0.82(0.32,2.14)$ & 0.6896 \\
\hline Cerebral vascular accident ever OR resection & 77 & $1.30(0.82,2.06)$ & 0.2565 \\
\hline Cranial OR peripheral neuropathy & 70 & $0.62(0.37,1.04)$ & 0.0676 \\
\hline Transverse myelitis & 3 & $3.70(0.34,40.79)$ & 0.2858 \\
\hline Estimated or measured GFR $<50 \%$ & 173 & $1.82(1.33,2.48)$ & 0.0002 \\
\hline Proteinuria $3.5 \mathrm{~g} / 24 \mathrm{hrs}$ & 56 & $2.97(1.66,5.32)$ & 0.0002 \\
\hline End-stage renal disease & 37 & $3.87(1.8,8.3)$ & 0.0005 \\
\hline Pulmonary hypertension & 86 & $2.25(1.44,3.53)$ & 0.0004 \\
\hline Pulmonary fibrosis & 60 & $1.02(0.61,1.72)$ & 0.9385 \\
\hline Shrinking lung & 1 & $\mathrm{~N} / \mathrm{C}$ & $\mathrm{N} / \mathrm{C}$ \\
\hline Pleural fibrosis & 25 & $0.99(0.43,2.25)$ & 0.9737 \\
\hline Pulmonary infarction OR resection & 2 & $\mathrm{~N} / \mathrm{C}$ & $\mathrm{N} / \mathrm{C}$ \\
\hline Angina OR coronary artery bypass & 48 & $0.60(0.33,1.12)$ & 0.1092 \\
\hline Myocardial infarction ever & 52 & $1.03(0.59,1.81)$ & 0.9111 \\
\hline Cardiomyopathy & 39 & $2.65(1.34,5.21)$ & 0.0049 \\
\hline Valvular disease & 22 & $1.23(0.52,2.89)$ & 0.6390 \\
\hline Pericarditis $>6$ months, OR pericardiectomy & 10 & $0.82(0.23,2.97)$ & 0.7635 \\
\hline Claudication x6 months & 24 & $1.17(0.51,2.69)$ & 0.7097 \\
\hline Minor tissue loss (pulp space) & 4 & $3.57(0.36,35.57)$ & 0.2774 \\
\hline Significant tissue loss ever & 11 & $1.14(0.34,3.8)$ & 0.8325 \\
\hline Venous thrombosis with swelling, ulceration, OR venous stasis & 19 & $0.81(0.32,2.07)$ & 0.6635 \\
\hline Infarction or resection of bowel & 83 & $0.56(0.35,0.89)$ & 0.0143 \\
\hline Mesenteric insufficiency & 3 & $1.83(0.17,20.21)$ & 0.6226 \\
\hline Chronic peritonitis & 1 & $\mathrm{~N} / \mathrm{C}$ & $\mathrm{N} / \mathrm{C}$ \\
\hline Stricture OR upper gastrointestinal tract surgery ever & 7 & $2.68(0.5,14.29)$ & 0.2480 \\
\hline Pancreatitis & 7 & $0.61(0.11,3.23)$ & 0.5596 \\
\hline Muscle atrophy or weakness & 21 & $1.10(0.46,2.66)$ & 0.8254 \\
\hline Deforming or erosive arthritis & 85 & $1.69(1.09,2.63)$ & 0.0194 \\
\hline Osteoporosis with fracture or vertebral collapse & 120 & $0.42(0.28,0.63)$ & 0.0000 \\
\hline Avascular necrosis & 76 & $2.50(1.54,4.04)$ & 0.0002 \\
\hline Osteomyelitis & 9 & $0.45(0.11,1.86)$ & 0.2711 \\
\hline Ruptured tendon & 29 & $1.55(0.72,3.36)$ & 0.2618 \\
\hline
\end{tabular}




\begin{tabular}{|l|c|c|c|}
\hline & \# of events among smokers & HR $^{\mathbf{1}}(\mathbf{9 5 \%} \mathbf{C I})$ & p-value \\
\hline Scarring chronic alopecia & 33 & $4.66(2.01,10.83)$ & $\mathbf{0 . 0 0 0 3}$ \\
\hline Extensive scarring or panniculum other than scalp and pulp space & 23 & $3.90(1.44,10.57)$ & $\mathbf{0 . 0 0 7 5}$ \\
\hline Skin ulceration (not due to thrombosis) for more than 6 months & 16 & $1.31(0.48,3.57)$ & 0.6003 \\
\hline Premature gonadal failure & 27 & $0.64(0.29,1.42)$ & 0.2712 \\
\hline Diabetes & 59 & $3.12(1.75,5.54)$ & $\mathbf{0 . 0 0 0 1}$ \\
\hline Malignancy (exclude dysplasia) & 99 & $0.82(0.55,1.24)$ & 0.3527 \\
\hline
\end{tabular}

${ }^{1}$ Adjusted for sex, age at diagnosis, and years of education 